Research Article

Check for updates

OPEN ACCESS

Received: Jul 30, 2020

Accepted: Oct 21, 2020

*Correspondence:

Soo-Jin Lee

Department of Occupational and

Environmental Medicine, Hanyang University

Seoul Hospital, 222-1 Wangsimni-ro,

Seongdong-gu, Seoul 04763, Korea.

E-mail: sjlee@hanyang.ac.kr

Copyright (c) 2020 Korean Society of Occupational \& Environmental Medicine This is an Open Access article distributed under the terms of the Creative Commons Attribution Non-Commercial License (https:// creativecommons.org/licenses/by-nc/4.0/) which permits unrestricted non-commercial use, distribution, and reproduction in any medium, provided the original work is properly cited.

ORCID iDs

Jiyoung Han (D)

https://orcid.org/0000-0002-3843-9583

Yangwoo Kim (iD)

https://orcid.org/0000-0003-3205-2780

Sooyeon Lee (iD)

https://orcid.org/0000-0002-5553-323X

Soo-Jin Lee (ID)

https://orcid.org/0000-0002-4938-1700

Abbreviations

ANOVA: analysis of variance; BMI: body mass index; Cl: confidence interval; COPD: chronic obstructive pulmonary disease; OR: odds ratio; SPT: skin prick test.

\section{Association between the prevalence of allergic reactions to skin prick tests and workplace types among agricultural workers in South Korea}

\author{
Jiyoung Han (ib) 1,2, Yangwoo Kim (1) 1,3, Sooyeon Lee (1) 1,2, and Soo-Jin Lee (i) 1,2* \\ 'Department of Occupational and Environmental Medicine, Hanyang University Hospital, Seoul, Korea \\ ${ }^{2}$ Department of Occupational and Environmental Medicine, Hanyang University College of Medicine, Seoul, \\ Korea \\ ${ }^{3}$ Graduate School of Public Health, Seoul National University, Seoul, Korea
}


Competing interests

The authors declare that they have no competing interest.

Author Contributions

Conceptualization: Lee SJ; Data curation: Han

J, Kim Y, Lee S; Investigation: Han J, Kim Y;

Writing - original draft: Han J; Writing - review

\& editing: Han J, Kim Y, Lee SJ.

\section{BACKGROUND}

There is currently a growing concern about the risks of hazardous airborne exposures on human health. Airborne hazards exist in many agricultural environments, such as crop storage and animal confinement, and they consist of hazardous gases, organic and inorganic dust, disinfectants, and pesticides. The most frequently occurring dangerous gases in agriculture are ammonia, carbon dioxide, hydrogen sulfide, methane, and nitrogen oxides [1]. In addition to gases, dust is a hazardous exposure during agricultural work. Small dust particles and mites are in grain, feed, animal hair, skin, and wastes, while fungi and mold spores are in grains and silage and they can attach to dust. Pesticides used on plants and livestock are another frequent hazardous exposure. All of these airborne hazards can be absorbed into the body by ingestion, inhalation, and/or absorption and have a detrimental effect on human health.

Agricultural processes may be associated with exposure to large quantities of organic dust and bioaerosols, which can cause allergic and immunotoxic reactions and respiratory disease in the workers [2-6]. Agriculture-related respiratory diseases were one of the firstrecognized occupational hazards. Respiratory disease is today an important clinical problem for agricultural workers. It was demonstrated that a significantly increased risk of respiratory morbidity and mortality among farmers and farm workers. This risk obtained despite the lower prevalence of smoking among them, compared with the general population, thus further implicating occupational risk factors for respiratory disease [7]. As shown by routinely collected statistics in the UK, Occupational respiratory disease represents an important cause of morbidity among farmers. In the European Community Respiratory Health Survey, the risk of asthma was analyzed by occupation and the highest risk was shown for farmers [8].

Farmers have different mortality and morbidity of respiratory diseases and prevalence of respiratory diseases and symptoms depending on where they work. In 2007, a study showed that the mortality of asthma was elevated for crop farm workers. Livestock farm workers had significantly elevated mortality for hypersensitivity pneumonitis and asthma [9]. The workers with livestock have a high prevalence and incidence of obstructive pulmonary disorders and asthmatic and nasal symptoms [10]. Greenhouse workers had been related to occupational asthma and chronic bronchitis [11] and they had high prevalence of self-reported respiratory symptoms [12]. In Croatia, a study determined hazardous levels of endotoxin, main allergen of dust mite Dermatophagoides pteronyysinus, and moulds in poultry houses. Also, significantly higher prevalence of work-related respiratory, eye and skin symptoms was found in poultry house workers compared to office workers [13].

It is already known that farmers have a higher risk of exposure to airborne hazards while working and have a greater risk of respiratory diseases and symptoms. Depending on which field they work in such as growing crops and animal husbandry, they have different risk of respiratory diseases and symptoms. We hypothesized that the type or level of airborne exposures in agriculture vary depending on where farmers mainly work, and that these different conditions may affect specific sensitization for allergens and may also be risk factors for respiratory diseases and symptoms. The objective of this study was to investigate whether certain types of agricultural workplaces are associated with the prevalence of allergic reactions in skin prick tests (SPTs) in South Korea. 


\section{METHODS}

\section{Subjects and definitions}

This was a cross-sectional study in which the study population was 149 farmers in South Korea in 2019. Volunteers filled out a self-reported questionnaire and were given SPTs. The self-reported questionnaire included demographic information, past history of diseases, diagnosed respiratory diseases, respiratory symptoms, smoking, drinking, pesticide exposure, and awareness of fine dust. There were 12 allergens for the SPTs. Among these farmers, we chose the subjects who met the following inclusion criteria: 1) those who completed the self-reported questionnaire, 2) those who responded positively for a histamine solution and without a negative skin reaction to a saline solution in the SPT, and 3) those who were working in either a greenhouse, a poultry house, or outside. Of the initial 166 subjects, a total of $149(89.6 \%)$ met the criteria and $17(11.4 \%)$ were excluded.

\section{A self-reported questionnaire}

The self-reported questionnaire included demographic information, past history of diseases, diagnosed respiratory diseases such as chronic obstructive pulmonary disease (COPD), asthma, and allergic rhinitis, respiratory symptoms, smoking, drinking, pesticide exposure, and awareness of fine dust. When the subjects filled out the questionnaires, there were helpers explaining the meaning of the questions and verifying what the subjects answered. The presence of respiratory disease was based on the questionnaire answer indicating a farmer had previously been diagnosed by a doctor. The respiratory symptoms we examined in the questionnaire were cough, sputum, chest discomfort or dyspnea, wheezing and sneezing, rhinorrhea, or nasal congestion. The symptoms of cough, sputum and chest discomfort or dyspnea were investigated to identify the prevalence of clinical symptoms of COPD. Wheezing as a typical symptom of asthma was investigated for the prevalence of the clinical symptom of it. And to identify the prevalence of the clinical symptoms of allergic rhinitis, the symptoms of sneezing, rhinorrhea, or nasal congestion were investigated through the questionnaire.

\section{Skin prick testing}

SPTs were performed on the volar side of a forearm by two trained doctors. Positive control (histamine), negative control (saline), and 12 allergens were included in the skin testing. The 12 allergens were: Dermatophagoides pteronyssinus (European house dust mite); Dermatophagoides farinae (U.S. house dust mite); Acarus siro (flour mite); dog epithelium; cat epithelium; Blattella germanica (German cockroach); pollen from mugwort, short ragweed, grass mix 5, and grey alder and white birch; and Alternaria alternata and Aspergillus fumigatus fungi. The participants were tested using the same allergen lots and the wheal outlines were read after 15 minutes. A skin reaction was considered positive if the reacted wheal diameter was equal to or greater than that of the positive control.

\section{Data entry and analysis}

Data were analyzed with the R statistical software v. 3.6.1 (The R Foundation, Vienna, Austria; https://www.r-project.org/). The participants were divided into three groups according to their primary workplace: greenhouse, poultry house, or outdoors. Participants were subdivided according to their positive reactions to the SPT allergens: animal allergens (mites, dog and cat epithelium, and German cockroach), and the fungal and plant allergens (pollens) described above. Analysis of variance (ANOVA) was used, followed by Tukey's post hoc test, for comparing the different workplace groups to determine if any were significantly different from the others. The comparison of categorical variables was done by $\chi^{2}$ tests. 
A logistic regression analysis was performed to estimate the odds ratios (ORs) at 95\% confidence intervals (CIs) for SPT sensitization depending on the types of workplaces. For the multivariate logistic regression analysis of the sensitization to SPT, farmers less than 35 years old and more than 75 years old were excluded, and the remaining subjects were grouped by age younger than or older than 60 . In previous studies, obesity and excess weight were reported to be risk factors for allergic diseases, and symptoms [14] and body mass index (BMI) had an association with skin reactivity of SPT [15]. Therefore, farmers whose BMI was $>30$ were excluded from this analysis. Symptoms of sneezing, rhinorrhea, or nasal congestion were included as variables in the multivariate model due to its clinical importance and its relation to allergic sensitization. The ORs were adjusted for sex, age and the symptoms of sneezing, rhinorrhea, or nasal congestion.

\section{Ethics statement}

Hanyang University Institutional Review Board approved this study (HYU-2019-03-012).

\section{RESULTS}

Among the 149 participants there were 90 men (60.4\%) and 59 women (39.6\%). The men's average age was 58.4 years and the women's was 59.4 years. There were 68 greenhouse workers, 44 poultry house workers, and 37 outdoor workers. Of the greenhouse workers, $67.6 \%$ were men and $32.4 \%$ were women; $63.6 \%$ of the poultry house workers were men and $36.4 \%$ were women; and $43.2 \%$ of the outdoor workers were men and $56.8 \%$ were women. Workers in their 60s made up the largest percentage in each subgroup, and there were significant differences in the demographic variables—-sex, age, smoking, and pesticide exposure (Table 1).

Table 1. Demographic characteristics of participants $(n=149)$

\begin{tabular}{|c|c|c|c|c|}
\hline Characteristics & Greenhouse $(n=68)$ & Poultry house $(n=44)$ & Outdoors $(n=37)$ & $p$-value ${ }^{a}$ \\
\hline Sex & & & & $0.044^{\mathrm{b}}$ \\
\hline Male & $46(67.6)$ & $28(63.6)$ & $16(43.2)$ & \\
\hline Female & $22(32.4)$ & $16(36.4)$ & $21(56.8)$ & \\
\hline Age (years) & $54.7 \pm 10.9$ & $58.6 \pm 10.8$ & $66.7 \pm 10.0$ & \\
\hline Age group (years) & & & & $<0.001^{\mathrm{b}}$ \\
\hline Under 40 & $11(16.2)$ & $4(9.1)$ & $1(2.7)$ & \\
\hline $40-49$ & $6(8.8)$ & $4(9.1)$ & $1(2.7)$ & \\
\hline $50-59$ & $20(29.4)$ & $11(25.0)$ & $3(8.1)$ & \\
\hline $60-69$ & $30(44.1)$ & $19(43.2)$ & $16(43.2)$ & \\
\hline $70-79$ & $1(1.5)$ & $6(13.6)$ & 11 (29.7) & \\
\hline Over 80 & $0(0.0)$ & $0(0.0)$ & $5(13.5)$ & \\
\hline Smoking & & & & $0.031^{b}$ \\
\hline Never & $32(47.1)$ & $22(50.0)$ & $27(73.0)$ & \\
\hline Ever & $36(52.9)$ & $22(50.0)$ & $10(27.0)$ & \\
\hline Drinking & & & & 0.255 \\
\hline Social & $46(67.6)$ & $27(61.4)$ & $29(78.4)$ & \\
\hline Heavy & $22(32.4)$ & $17(38.6)$ & $8(21.6)$ & \\
\hline BMI $\left(\mathrm{kg} / \mathrm{m}^{2}\right)$ & & & & 0.947 \\
\hline$<30 \mathrm{~kg} / \mathrm{m}^{2}$ & $59(86.8)$ & $39(88.6)$ & $32(86.5)$ & \\
\hline$\geq 30 \mathrm{~kg} / \mathrm{m}^{2}$ & $9(13.2)$ & $5(11.4)$ & $5(13.5)$ & \\
\hline Pesticide & & & & $0.001^{b}$ \\
\hline Unexposed & $12(17.4)$ & $19(43.2)$ & $4(10.8)$ & \\
\hline Exposed & $57(82.6)$ & $25(56.8)$ & $33(89.2)$ & \\
\hline
\end{tabular}

Values are expressed as mean \pm standard deviation or number (\%).

BMI: body mass index; ANOVA: analysis of variance.

${ }^{a}$ Result of ANOVA F-test, ${ }^{b} p$-value $<0.05$ (significant level). 
Table 2. Prevalence of respiratory diseases and symptoms of farmers according to their type of workplace

\begin{tabular}{|c|c|c|c|c|}
\hline Respiratory diseases and symptoms & Greenhouse $(n=68)$ & Poultry house $(n=44)$ & Outdoors $(n=37)$ & $p$-value ${ }^{a}$ \\
\hline COPD & $0(0.0)$ & $3(6.8)$ & $0(0.0)$ & $0.026^{b}$ \\
\hline Asthma & $3(4.4)$ & $1(2.3)$ & $1(2.7)$ & 0.802 \\
\hline Allergic rhinitis & $9(13.2)$ & $3(6.8)$ & $5(13.5)$ & 0.521 \\
\hline Cough & $6(8.8)$ & $2(4.5)$ & $0(0.0)$ & 0.153 \\
\hline Sputum & $4(5.9)$ & $2(4.5)$ & $0(0.0)$ & 0.335 \\
\hline Chest discomfort or dyspnea & $5(7.4)$ & $3(6.8)$ & $6(16.2)$ & 0.259 \\
\hline Wheezing & $1(1.5)$ & $4(9.1)$ & $0(0.0)$ & $0.039^{b}$ \\
\hline Sneezing, rhinorrhea, or nasal congestion & $15(22.1)$ & $7(15.9)$ & $12(32.4)$ & 0.206 \\
\hline
\end{tabular}

Values are expressed as number (\%).

COPD: chronic obstructive pulmonary disease; ANOVA: analysis of variance.

${ }^{a}$ Result of ANOVA F-test, ${ }^{b} p$-value $<0.05$ (significant level).

Table 2 shows the prevalence of diseases such as COPD, asthma, and allergic rhinitis and the prevalence of symptoms such as cough, sputum, chest discomfort or dyspnea, wheezing and sneezing, rhinorrhea, or nasal congestion of workers in greenhouses, poultry houses, and outdoors. There were 3 farmers ( $6.8 \%$ of the poultry house workers) who were diagnosed with COPD only in a poultry workplace, which was significantly different from the other 2 workplaces. The prevalence of allergic rhinitis was similar in the greenhouse group and the outdoor group. Among the clinical symptoms, wheezing was the only statistically significantly different symptom in these three groups. The prevalence of the symptoms of sneezing, rhinorrhea, or nasal congestion of the poultry house workers was lower than that of others, but there was no significant difference.

Looking at the SPT responses to the 12 allergens (Table 3), the prevalence of any allergen was the highest in the greenhouse workers, and significant differences were observed among the subgroups. The difference between the greenhouse workers and the outdoor workers had a $p$-value $=0.016$, while differences between the other groups were not significant. The highest sensitization rate in greenhouse workers was observed to animal allergens, especially house

Table 3. SPT results of farmers according to their type of workplaces

\begin{tabular}{|c|c|c|c|c|}
\hline Allergen tested & Greenhouse $(n=68)$ & Poultry house $(n=44)$ & Outdoors $(n=37)$ & $p$-value ${ }^{a}$ \\
\hline Any allergen & $21(30.9)$ & $7(15.9)$ & $3(8.1)$ & $0.015^{\mathrm{b}}$ \\
\hline Any animal & $13(19.1)$ & $4(9.1)$ & $0(0.0)$ & $0.011^{b}$ \\
\hline House dust mites & $13(19.1)$ & $4(9.1)$ & $0(0.0)$ & $0.011^{b}$ \\
\hline Dermatophagoides pteronyssinus & $11(16.2)$ & $3(6.8)$ & $0(0.0)$ & $0.020^{b}$ \\
\hline Dermatophagoides farinae & $11(16.2)$ & $4(9.1)$ & $0(0.0)$ & $0.030^{b}$ \\
\hline \multicolumn{5}{|l|}{ Storage mite } \\
\hline Acarus siro & $0(0.0)$ & $2(4.5)$ & $0(0.0)$ & 0.089 \\
\hline Pets & $0(0.0)$ & $0(0.0)$ & $0(0.0)$ & \\
\hline Dog epithelium & $0(0.0)$ & $0(0.0)$ & $0(0.0)$ & \\
\hline Cat epithelium & $0(0.0)$ & $0(0.0)$ & $0(0.0)$ & \\
\hline Blattella germanica & $1(1.5)$ & $0(0.0)$ & $0(0.0)$ & 0.549 \\
\hline Any plants & $11(16.2)$ & $3(6.8)$ & $3(8.1)$ & 0.241 \\
\hline Weed pollen & $6(8.8)$ & $1(2.3)$ & $1(2.7)$ & 0.229 \\
\hline Mugwort & $6(8.8)$ & $1(2.3)$ & $0(0.0)$ & 0.083 \\
\hline Ragweed & $0(0.0)$ & $0(0.0)$ & $1(2.7)$ & 0.218 \\
\hline Grass mix 5 & $8(11.8)$ & $0(0.0)$ & $1(2.7)$ & $0.023^{b}$ \\
\hline Grey alder, white birch & $3(4.4)$ & $2(4.5)$ & $2(5.4)$ & 0.972 \\
\hline Any fungus & $1(1.5)$ & $1(2.3)$ & $0(0.0)$ & 0.670 \\
\hline Alternaria alternata & $0(0.0)$ & $0(0.0)$ & $0(0.0)$ & \\
\hline Aspergillus fumigatus & $1(1.5)$ & $1(2.3)$ & $0(0.0)$ & 0.670 \\
\hline
\end{tabular}

Values are expressed as number (\%).

SPT: skin prick test; ANOVA: analysis of variance.

${ }^{a}$ Result of ANOVA F-test, ${ }^{b} p$-value $<0.05$ (significant level). 
dust mites ( $D$. pteronyssinus, $p=0.020, D$. farinae, $p=0.030$ ), while the lowest skin reactivity was detected to fungal allergens. The sensitivity to animal allergens was significantly different between the greenhouse workers and the outdoor workers ( $p=0.009)$. Those 2 groups sensitivity to grass mix allergen had a $p=0.023$, while that between the greenhouse workers and poultry house workers was $p=0.028$.

From logistic analysis for positive SPT (Fig. 1), sex, age, BMI and pesticide were not associated with the SPT results. The prevalence of symptoms of sneezing, rhinorrhea, or nasal congestion was significantly associated with the sensitization to SPT (OR: 5.13, 95\% CI: 1.82-14.47). When looking at the association of the SPT sensitization with the types of workplaces, greenhouse workers had higher risk of SPT positive for allergen tested than outdoor workers, which is statistically significant (OR: 4.84, 95\% CI: 1.28-18.31). Poultry house workers had higher risk on skin reactivity of SPT compared to outdoor workers, but it was not statistically significant (OR: 1.08, 95\% CI: 0.22-5.26).

The adjusted ORs of the prevalence of positive SPTs are given in Table 4; associations are reported as adjusted ORs with 95\% CIs. Compared to outdoor workers, there was a strong

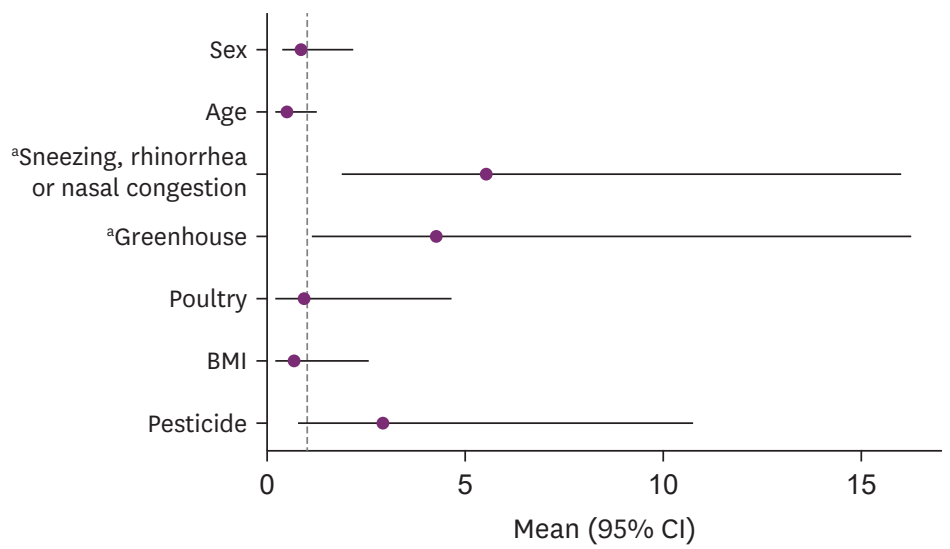

Fig. 1. Odds ratio of logistic analysis for positive SPT.

$\mathrm{Cl}$ : confidence interval; BMI: body mass index; SPT: skin prick test.

${ }^{a} p$-value $<0.05$ (significant level).

Table 4. The adjusted odd ratios of the prevalence of positive SPT of farmers

\begin{tabular}{|c|c|c|}
\hline Variables & Positive SPT reaction to any allergen & $p$-value ${ }^{a}$ \\
\hline \multicolumn{3}{|l|}{ Sex } \\
\hline Male & 1 & 0.954 \\
\hline Female & $1.03(0.34-3.00)$ & \\
\hline \multicolumn{3}{|l|}{ Age (years) } \\
\hline$<60$ & 1 & 0.517 \\
\hline$\geq 60$ & $0.70(0.24-2.08)$ & \\
\hline \multicolumn{3}{|c|}{ Sneezing, rhinorrhea, or nasal congestion } \\
\hline Negative & 1 & $0.002^{b}$ \\
\hline Positive & $6.64(2.06-23.63)$ & \\
\hline \multicolumn{3}{|l|}{ Workplace } \\
\hline Outdoors & 1 & \\
\hline Greenhouse & $5.55(1.32-32.24)$ & $0.032^{\mathrm{b}}$ \\
\hline Poultry house & $1.18(0.20-7.83)$ & 0.582 \\
\hline
\end{tabular}


association between the greenhouse workers with a positive SPT (adjusted OR: 5.55, 95\% CI: 1.32-32.24), and there was also a marked association between a positive SPT with symptoms of sneezing, rhinorrhea, or nasal congestion (adjusted OR: 6.64, 95\% CI: 2.06-23.63).

\section{DISCUSSION}

Farmers have more respiratory disorders than the general population $[16,17]$. and it is common that work-related environmental factors affect their respiratory systems [18]. Farmers have different exposures to work-related airborne dusts and working environment according to their types of workplaces, but few studies have examined such exposures and their health effects on farmers. This study investigated the association of SPT sensitization with farmers' workplaces.

This cross-sectional study showed that greenhouse workers had a significantly higher prevalence of positive SPT reaction to any allergen than the other two groups. In particular, greenhouse workers had the highest SPT positivity to house dust mites, and this was significantly different from the outdoor workers. And also the greenhouse workers' sensitization to grass mix 5 pollen was significantly higher than that of poultry house workers. From the multivariate logistic regression analysis of the prevalence of positive SPT reactions, SPT positivity was associated with working in a greenhouse and having the symptoms of sneezing, rhinorrhea, or nasal congestion.

These results can be explained by differences in the type or level of airborne exposures at workplace. In a study in Poland, SPTs were performed with common allergens and fungal extracts in museum workers who were exposed to fungi and mites in the workplace. The most frequent allergens yielding SPT positivity among the workers were house dust mites ( $D$. pteronyssinus, $D$. farinae). Thirty percent of museum employees were sensitized to at least one of the fungal allergens. In addition, the study population had higher prevalence of SPT positivity than the general population [19]. The Polish study showed the association between allergen exposure and SPT sensitization in the working environment. Workplaces associated with mite-related illnesses include greenhouses, poultry houses, livestock farms, animal housing facilities, and grain storage facilities [20]. Mites thrive in warm and humid environments [21], and dust mites infest organic particles in dusts such as floor dust. Considering the environments where house dust mites preferentially live, working in a greenhouse with high temperature and humid conditions can increase exposures to house dust mites [11]. Similarly, the sensitization of greenhouse workers to grass mix 5 pollen was significantly higher than that of poultry house workers. It can also be explained by the higher level of grass pollens in greenhouses than in poultry houses. Therefore, it seems likely that working in a greenhouse was more likely to be exposed to allergens than the other two groups, so there was a possibility that the SPT sensitivity was higher than others [10,22-24].

The demographic characteristics of participants may also affect the findings of this study. In previous studies, skin reactivity associated with age and BMI [15,25]. Allergic reactions decreased with age and increased with BMI. The average age of people working in greenhouses was 54.7 years old (10.9 years of standard deviation). And the farmers under the age of 40 were the highest at $16.2 \%$ and over 70 years old were the lowest at $1.5 \%$ in the 3 groups. On the other hand, the average age of farmers working outdoors was 66.7 years old (10.0 years of standard deviation) with $43.2 \%$ of those over 70 years old. Because of the 
difference in age distribution between two groups, it was possible that the prevalence of SPT positivity of greenhouse workers was higher than that of outdoor workers. In BMI, the average of greenhouse workers was $25.1 \mathrm{~kg} / \mathrm{m}^{2}$ (standard deviation $2.7 \mathrm{~kg} / \mathrm{m}^{2}$ ) and the average of outdoor workers was $24.6 \mathrm{~kg} / \mathrm{m}^{2}$ (standard deviation $2.3 \mathrm{~kg} / \mathrm{m}^{2}$ ). Although the BMI of the 2 groups did not differ significantly, the sensitivity of the greenhouse workers to SPT was high. This was consistent with previous studies showing that people with high BMI are susceptible to allergic reactions.

In our study, the prevalence of SPT sensitization was correlated with sneezing, rhinorrhea, or nasal congestion. Skin prick testing is a technique for detecting type I sensitizations against inhalant allergens. In a study in Europe, approximately $\geq 60 \%$ of all sensitizations were clinically relevant. It demonstrated that the clinical relevance of inhalant allergen sensitizations might significantly differ depending on the allergen [26]. In a study investigating SPT sensitivity to allergen exposures and allergy symptoms in veterinary medicine students in the Netherlands, being sensitized to farm animals, horse, cat or dog allergens was strongly and positively associated with the prevalence of symptoms including wheezing, asthma attack, itchy and skin [27]. SPT positivity identifies sensitizations to a particular allergen but does not determine the clinical relevance of this sensitization. There is a need for further investigation to determine the incidence of sensitization and allergic symptoms.

When comparing the symptoms of sneezing, rhinorrhea, or nasal congestion of participants (Table 2), the prevalence of the symptoms of outdoor workers $(32.4 \%)$ was higher than that of greenhouse workers (22.1\%). However, greenhouse workers were more likely to have the prevalence of SPT positivity compared to outdoor workers. In a study, SPT sensitizations had a relationship with clinical symptoms. It demonstrated that the clinical relevance of sensitizations might significantly differ depending on the allergen [26]. In Northern Europe, a study was conducted on the SPT sensitization of storage mites and house dust mites, and the prevalence of allergy symptoms and diseases. As a result of the study, the risk of allergic symptoms and diseases was different according to the type of allergen sensitized in SPT [28]. As shown in Table 3, there may be differences in the prevalence of the symptoms of sneezing, rhinorrhea, or nasal congestion due to different SPT sensitizing allergens in each subgroup. However, among greenhouse workers and outdoor workers, there was no correlation between SPT results and the symptoms of sneezing, rhinorrhea, or nasal congestion. More studies are needed to explain the association between the respiratory symptoms and diseases and the SPT results in each subgroup.

Among the baseline respiratory diseases and clinical symptoms in our study, the prevalence of COPD and the prevalence of wheezing were significantly different in the subgroups and were the highest in the poultry house workers. In previous studies poultry house workers were exposed to dust originating from poultry residues, molds, and feathers, and it is known that these exposures increase the risk of asthma, chronic bronchitis, COPD, allergic alveolitis, and organic dust toxic syndrome [9,29]. In addition, a high prevalence of nasal symptoms was identified in poultry house workers [13]. In this study, the prevalence of COPD and wheezing, a symptom of asthma, were high among farmers working in poultry houses. However, there were no significant differences between the three subgroups in other respiratory diseases or respiratory symptoms. In addition, the risk of asthma and the prevalence of symptoms of sneezing, rhinorrhea, or nasal congestion among poultry house workers were not higher than those of other groups. 
In this study, there was a correlation between the prevalence of positive SPT reactions and the types of workspaces. In addition, the positive SPT reactions was also associated with the prevalence of symptoms of sneezing, rhinorrhea, or nasal congestion in those who participated in the study. However, there was no association between the prevalence of respiratory diseases and symptoms and the prevalence of positive SPT reactions in each subgroup. A previous study investigated the effect of indoor allergens on asthma morbidity [30], and other research found a positive association between sensitization to aeroallergens and the development of asthma and other allergic diseases [31-33]. In a study of Northern Europe, the risk of allergic symptoms and diseases was different according to the type of allergen sensitized in SPT [28]. Considering the results of this study and previous studies, there is a need for further investigation to assess the risk of respiratory diseases and symptoms according to the type or level of allergens in each workplace.

The limitations of the present study are that more subjects in all subgroups are needed for more accurate results, and the cross-sectional analysis design does not allow for inference of causality. Moreover, this study was not able to fully assess the factors that could influence SPT results such as the farmers' years of working experience, their average working hours per day, and the types of particulate matter in their working environments. It is difficult to specify a causative allergen in occupation-related diseases and symptoms, so assessing specific dust types depending on workplace type and working period helps to identify causative allergens and their effects on human health.

In conclusion, our study shows that the prevalence of positive SPT reactions have an association with the type of workplace. Farmers working inside greenhouses were more sensitized to SPTs, specifically for house dust mites and grass mix pollen, than were those in poultry houses or outdoors. It could be explained by the environment of the workplace and the type and level of exposures according to the type of workplace. It was also likely that it was caused by differences between groups of individual factors such as age and BMI that affect SPT sensitization.

\section{CONCLUSIONS}

The types of workplaces were associated with the prevalence of allergic sensitization. This could be explained by the difference in working environment and the different types and levels of airborne exposures in each workplace. It was also likely that it was caused by differences between groups of individual factors such as age and BMI that affect SPT sensitization.

\section{ACKNOWLEDGEMENTS}

We thank the farmers for their support in surveys and medical examinations. This work was carried out with the support of "Cooperative Research Program for Agriculture Science and Technology Development (Project No. PJ01426903)" Rural Development Administration, Republic of Korea. 


\section{REFERENCES}

1. Donham KJ, Popendorf WJ. Ambient levels of selected gases inside swine confinement buildings. Am Ind Hyg Assoc J 1985;46(11):658-61.

PUBMED | CROSSREF

2. Danuser B, Monn C. Endotoxins in the workplace and in the environment. Schweiz Med Wochenschr 1999;129(12):475-83. PUBMED

3. Lacey J, Crook B. Fungal and actinomycete spores as pollutants of the workplace and occupational allergens. Ann Occup Hyg 1988;32(4):515-33. PUBMED | CROSSREF

4. Lacey J, Dutkiewicz J. Bioaerosols and occupational lung disease. J Aerosol Sci 1994;25(8):1371-404. CROSSREF

5. Radon K, Danuser B, Iversen M, Monso E, Weber C, Hartung J, et al. Air contaminants in different European farming environments. Ann Agric Environ Med 2002;9(1):41-8. PUBMED

6. Radon K, Monso E, Weber C, Danuser B, Iversen M, Opravil U, et al. Prevalence and risk factors for airway diseases in farmers--summary of results of the European Farmers' Project. Ann Agric Environ Med 2002;9(2):207-13. PUBMED

7. Respiratory health hazards in agriculture. Am J Respir Crit Care Med 1998;158(5 Pt 2):S1-76. PUBMED | CROSSREF

8. Linaker C, Smedley J. Respiratory illness in agricultural workers. Occup Med (Lond) 2002;52(8):451-9. PUBMED | CROSSREF

9. Greskevitch M, Kullman G, Bang KM, Mazurek JM. Respiratory disease in agricultural workers: mortality and morbidity statistics. J Agromed 2007;12(3):5-10. PUBMED | CROSSREF

10. Viegas S, Faísca VM, Dias H, Clérigo A, Carolino E, Viegas C. Occupational exposure to poultry dust and effects on the respiratory system in workers. J Toxicol Environ Health A 2013;76(4-5):230-9. PUBMED | CROSSREF

11. Monsó E. Occupational asthma in greenhouse workers. Curr Opin Pulm Med 2004;10(2):147-50. PUBMED | CROSSREF

12. Adhikari A. Exposure to microorganisms and aeroallergens among greenhouse workers worldwide and associated respiratory diseases. MOJ Public Health 2016;4(3):88-92. CROSSREF

13. Rimac D, Macan J, Varnai VM, Vučemilo M, Matković K, Préster L, et al. Exposure to poultry dust and health effects in poultry workers: impact of mould and mite allergens. Int Arch Occup Environ Health 2010;83(1):9-19. PUBMED | CROSSREF

14. Chen Y, Rennie D, Cormier Y, Dosman J. Association between obesity and atopy in adults. Int Arch Allergy Immunol 2010;153(4):372-7. PUBMED | CROSSREF

15. Park DY, Kim YS, Kim JH, Kang JW. Association of body mass index and other factors with histamine skin reactivity in adults with allergic nasal symptoms [Internet]. Am J Rhinol Allergy 2015;29(6):e160-3. PUBMED | CROSSREF

16. Heller RF, Kelson MC. Respiratory disease mortality in agricultural workers in eight member countries of the European community. Int J Epidemiol 1982;11(2):170-4. PUBMED | CROSSREF

17. Torén K, Hörte LG, Järvholm B. Occupation and smoking adjusted mortality due to asthma among Swedish men. Br J Ind Med 1991;48(5):323-6. PUBMED | CROSSREF

18. Poole JA. Farming-associated environmental exposures and effect on atopic diseases. Ann Allergy Asthma Immunol 2012;109(2):93-8 PUBMED | CROSSREF

19. Wiszniewska M, Walusiak-Skorupa J, Pannenko I, Draniak M, Palczynski C. Occupational exposure and sensitization to fungi among museum workers. Occup Med (Lond) 2009;59(4):237-42. PUBMED | CROSSREF

20. Scott R. Section IV. Physical and biological hazards in the workplace. In: Scott R, editor. Basic Concepts of Industrial Hygiene. New York: Routledge; 2018. 
21. Acevedo N, Zakzuk J, Caraballo L. House dust mite allergy under changing environments. Allergy Asthma Immunol Res 2019;11(4):450-69.

PUBMED | CROSSREF

22. Zuskin E, Schachter EN, Mustajbegovic J. Respiratory function in greenhouse workers. Int Arch Occup Environ Health 1993;64(7):521-6.

PUBMED | CROSSREF

23. Rodolfi M, Lorenzi E, Picco AM. Study of the occurrence of greenhouse microfungi in a botanical garden. J Phytopathol 2003;151(11):591-9.

CROSSREF

24. Bessot JC, Blaumeiser M, Kopferschmitt MC, Pauli G. Occupational asthma in an agricultural setting. Rev Mal Respir 1996;13(3):205-15.

PUBMED

25. Montealegre F, Meyer B, Chardon D, Vargas W, Zavala D, Hart B, et al. Comparative prevalence of sensitization to common animal, plant and mould allergens in subjects with asthma, or atopic dermatitis and/or allergic rhinitis living in a tropical environment. Clin Exp Allergy 2004;34(1):51-8. PUBMED | CROSSREF

26. Burbach GJ, Heinzerling LM, Edenharter G, Bachert C, Bindslev-Jensen C, Bonini S, et al. GA(2)LEN skin test study II: clinical relevance of inhalant allergen sensitizations in Europe. Allergy 2009;64(10):1507-15. PUBMED | CROSSREF

27. Samadi S, Spithoven J, Jamshidifard AR, Berends BR, Lipman L, Heederik DJ, et al. Allergy among veterinary medicine students in The Netherlands. Occup Environ Med 2012;69(1):48-55. PUBMED | CROSSREF

28. Jõgi NO, Kleppe Olsen R, Svanes C, Gislason D, Gislason T, Schlünssen V, et al. Prevalence of allergic sensitization to storage mites in Northern Europe. Clin Exp Allergy 2020;50(3):372-82. PUBMED | CROSSREF

29. Nordgren TM, Bailey KL. Pulmonary health effects of agriculture. Curr Opin Pulm Med 2016;22(2):144-9. PUBMED | CROSSREF

30. Lewis SA, Weiss ST, Platts-Mills TA, Burge H, Gold DR. The role of indoor allergen sensitization and exposure in causing morbidity in women with asthma. Am J Respir Crit Care Med 2002;165(7):961-6. PUBMED | CROSSREF

31. Sears MR, Burrows B, Flannery EM, Herbison GP, Holdaway MD. Atopy in childhood. I. Gender and allergen related risks for development of hay fever and asthma. Clin Exp Allergy 1993;23(11):941-8. PUBMED | CROSSREF

32. Arshad SH, Tariq SM, Matthews S, Hakim E. Sensitization to common allergens and its association with allergic disorders at age 4 years: a whole population birth cohort study. Pediatrics 2001;108(2):E33. PUBMED | CROSSREF

33. Sears MR, Herbison GP, Holdaway MD, Hewitt CJ, Flannery EM, Silva PA. The relative risks of sensitivity to grass pollen, house dust mite and cat dander in the development of childhood asthma. Clin Exp Allergy 1989;19(4):419-24.

PUBMED | CROSSREF 